\title{
An Overview of Quality of Life across Asia: A Sociological Appraisal
}

\author{
Mohammad Taghi Sheykhi \\ Department of Professor Emeritus of Sociology, Alzahra University, Tehran, Iran.
}

*Corresponding Author: Mohammad Taghi Sheykhi, Department of Professor Emeritus of Sociology, Alzahra University, Tehran , Iran.

Received Date: October 23, 2021; Accepted Date: Decemberr 16, 2021; Published Date: January 06,2022

Citation: Mohammad Taghi Sheykhi (2022) An Overview of Quality of Life across Asia: A Sociological Appraisal. J. Addiction Research and Adolescent Behaviour 5(1); DOI: 10.31579/2688-7517/032

Copyright: () 2022, Mohammad Taghi Sheykhi ,This is an open access article distributed under the Creative Commons Attribution License, which permits unrestricted use, distribution, and reproduction in any medium, provided the original work is properly cited.

\begin{abstract}
In terms of sociology, quality of life was propounded in Asia since new industrialization entered the countries. Since then, there has been a competition among the countries of the region to reach higher and improved quality of life. To reach that goal, various plans have been put into practice. For a better quality of life, educational development was prioritized as a key factor to penetrate other dimensions of development such as health, industries, communications, and many more. In this way, all the dimensions started improving, and the process of which resulted in the decline of mortality rate, and the gradual increase in life expectancy. Through change in quality of life, all variables of life such as fertility, marriage age, hygiene and health, nutrition, family income, public culture, communications, etc. were positively affected. But, all the Asian countries have not changed in the same manner. For example, quality of life in East Asia was more affected than other parts of the continent. However, the competition is still continuing. Policy-makers and planners have come to know the reality of ever improving quality of life. Different scales/ degrees of quality of life may be shown in terms of life expectancy in Afghanistan and Japan which is 42 years for the first, and 85 years for Japan.
\end{abstract}

Keywords: image of asian societies; measuring normal life; lifestyle; life expectancy; sociology.

\section{Introduction}

Quality of life is comprised of various elements such as education, income, employment, health, and the like. Though many Asian countries are dynamic and growing well, some are different and lag behind. They are overall of lower quality of life. Quality of life is a phenomenon to be made. Many Asian countries are in a sort of competition to further raise their quality of life. They are building their economies, expanding their educational systems, raising human power's per capita income and so on, to create the infrastructure necessary. Factors such as high population growth, low average age of marriage, low life expectancy, low literacy rate among young population groups, especially women, each in turn slows down the development process within communities in Asia. Such a development process negatively affects future generations as well. Therefore, many Asian countries need more investment, appropriate demographic planning, improving the status of women, and the like to replace poverty with security, well-being and higher quality of life. Standard indicators of quality of life include wealth, employment, the environment, physical and mental health, education, recreation and leisure time, social belonging, security and freedom (Derek, 2009); (Nussbaum, 1993); (Barcaccia, 2013). As projected, the world population will increase to over 10 billion by the year 2050, Asia as the most populous continent of the world need to be more thought of as far as quality of life is concerned (WPDS, 2021).
Demographics are constantly changing, especially in Asia, the world's most populous continent. Changing the social indicators of the Asian region is mainly done to achieve socio-economic development and improve the quality of life. For example, the adoption of new demographic policies in China during the years 1979-1991 was mainly aimed at improving the quality of life and subsequently improving products and services in that society. Since the emergence and introduction of the GDP index, it has always been recognized as the most important indicator of economic performance of countries. This index paves the way for a better quality of life (Costanza et al. 2009). Improving social and demographic indicators also ultimately leads to longer life expectancy for different groups of the population, as well as achieving greater health among different social strata. In recent decades, Asian societies have generally experienced this transformation; That is, they have adopted demographic planning and new social policies; simply because they have been lifted out of poverty, and subsequently to a higher economic and social position. In this way, higher per capita income, education, health, security and the like can be achieved. The set of mentioned indicators helps to improve the quality of life in any society.

\section{Method of Research}

Methodology used in the present article is of qualitative type. In that, various paradigms have been used to find out about the facts regarding 
pandemics during the history. Qualitative research usually studies people, events or areas in their natural settings. In finding facts for the research, the researcher engaged in careful data collection and thoughtful analysis of what was relevant. In the documentary research applied for the present research, printed and written materials were widely regarded. The research was performed as a qualitative library-type in which the researcher had to refer to the relevant and related sources. In the current research, various documents were thoroughly investigated, and the needful inferences were made. The data fed by the investigator in the present article is hopefully reliable. Though literature on pandemics is very limited, yet the author tried to investigate many different resources in order to elicit the necessary information to build up the text.

\section{The image of Asian societies}

Differences and conflicts between 29 countries and societies in the Asian region are typically examined in terms of priorities, values, lifestyle, life satisfaction, and overall quality of life, including happiness, enjoyment, and progress. Out of the total number of Asian countries, 29 cases have been evaluated as a sample and according to the dimensions of their various indicators. Because factors such as industry, development, education, urbanization, etc. have affected the way of life and the set of value systems, the evaluation of such indicators is of great social and cultural importance. Improving these indicators has led to the improvement of many variables, which are generally referred to as improving the quality of life. Therefore, the reform of its social indicators has a pivotal and decisive role in this movement. It should be noted that in addition to the reform of such indicators, other areas of development, renovation, services and the like must be realized. Therefore, in the present age, multi-axis investments in such societies are generally on the agenda of planners and policy makers. In general, it can be explained that the development of a society is more related to the quality of life of its people, including freedom of choice, personal security, education, etc., than the amount of material wealth (Sen: 1985; 2000).

Although the Asian region itself is a dynamic and diverse region, its demographic characteristics have not been comprehensively and scientifically assessed. Different countries of the Asian continent, which themselves have taken steps towards development and modernization, face different social characteristics. The non-standard and disproportion of many social indicators in many Asian societies has caused such societies to face inconsistent social and cultural indicators. For example, demographic rates such as high population growth, low average age of marriage, disproportionate (increasing) fertility, low life expectancy, low literacy rate among young population groups, especially women, each in turn slows down the development process in such Provided by communities. Such a development process also negatively affects future generations; in a way, the low quality of life of the current generation inevitably affects the next generation as well. Hence, many Asian societies need more investment, appropriate demographic planning, improving the status of women, and so on, so that they can replace poverty and underdevelopment with security, well-being, and quality of life in their communities.

The geographical, demographic, economic, etc. characteristics of this region are very diverse, and it has left different characteristics. Despite these differences, many Asian societies have achieved many development goals by pursuing progressive population policies; That is, for example, they have increased their GDP, increased the public purchasing power of society, and as a result have gained access to many economic, welfare and service resources. This trend has generally led to a different quality of life for these communities compared to their past. Therefore, one of the top priorities of Asian societies is investing in the population sector. It is noteworthy that the United Nations, and many of its subordinate bodies such as the World Health Organization, the World Food and Agriculture Organization, UNICEF, UNESCO and the like, in advancing the goals of population, food, health and education programs of such communities (Asian communities) have played an effective role. Scope has also provided constructive guidance to Asian communities over the past 40 years.

Economic development, the future situation in terms of population and the like, is largely fragile and vulnerable. Many Asian countries have been affected by these factors with different social, economic and demographic indicators, which has affected their quality of life. In societies such as China, South Korea and Singapore, following the pursuit of effective demographic policies and other development plans in recent decades, such countries have enjoyed high per capita income, adequate nutrition and health, quality educational facilities, etc., which themselves The lives of different strata have had a decisive influence; In a way that future generations will be positively affected in these communities. Meanwhile, some other countries in the region, such as Cambodia, Burma, Bangladesh and the like, with their unsuitable demographic indicators, have high population growth, and consequently the quality of life index and the enjoyment of facilities needed by citizens in these communities in a lower limit has been announced.

\section{Asia with wide differences}

It is no exaggeration to say that the Asian region has many differences. Compared to the continent of Europe, where there are many similarities, Asia faces linguistic, cultural, geographical, economic, social, demographic, and other diversity; That is, the situation itself must be studied and evaluated comparatively. The European Commission (2009) has also targeted initiatives to measure and improve the factors that lead to social progress, wealth and health. The process of this development assumes environmental protection, biodiversity and social integration as important areas of economic growth.

For example, demographically, China's population is estimated at more than 1.3 billion and India's population at 1.2 billion (WPDS: 2012); The Maldives and Brunei each have populations of about 400,000. Its demographic differences bring with it a great deal of cultural, social and economic diversity of different strata. Therefore, larger countries in terms of population, themselves need more investment, appropriate and codified planning, health promotion, treatment and education; In such a way that they meet the many needs of their citizens. Thus, sociology has more applications in such societies than in geographically smaller and less populous countries. Evidence of this claim is witnessed by the two great countries China and India in Asia, which are always active in a variety of development plans in these societies.

Similarly, while the adult literacy rate is estimated at $28.1 \%$ in Afghanistan and $99.5 \%$ in Kazakhstan, it has brought them a different quality of life. Early marriage at one time, and subsequent separation from education, makes the next generation illiterate. In contrast, if the current parents have the skills, expertise and literacy, there is a greater guarantee for the literacy of their children (future generation). Thus, the cycle of educational poverty negatively affects future generations, and at the same time investing in educating the younger generation, as seen today in Kazakhstan among developing countries, is itself a guarantee for the quality of life of future generations. In that society.

On the other hand, the 45-year life expectancy index in Afghanistan and the 82-year life expectancy index in Japan provide different levels of productivity in these societies and between new generations. Self-efficacy is achieved in a situation where there is a higher life expectancy in general in a given society. For example, life expectancy of about 45 years in Afghanistan does not bring high returns to the population; while the 82year life expectancy index in Japanese society has allowed all citizens to use their full potential, and their high productivity, further enhance the economic and social resources of that society. The latter, or the state of high life expectancy, also brings with it a high quality of life in general. Such a positive cycle and sequence also positively affects the next 
generations, and provides the optimal use of resources; That is, a set of conditions that lead to an improvement in the quality of life.

The per capita GDP of about \$1,000 a year in Afghanistan and \$ 57,200 in Singapore has also created different quality of life expectations. In the context of improving other areas and increasing per capita GDP, citizens generally enjoy more and higher opportunities; in a way, in addition to having more participation in the production of services, they also benefit from more products and services. This process leads to a higher quality of life and more related consequences for them. Today, many Asian countries are trying to achieve higher economic success by reforming their population index, and thus make good use of available resources.

Indicators of Internet use in Cambodia show different social connections per 79 per 1,000, compared to 389 per 1,000 in China. Many countries in the Asian region have made significant progress in the social, economic and cultural fields following the expansion of their communication networks. In other words, a kind of social balance has emerged in these societies. This move has also greatly reduced class differences, while improving the quality of life. Therefore, one of the ways to achieve socioeconomic development and subsequently improve living standards is to invest more in the communication networks.

On the other hand, in terms of the priorities of daily life, there are significant differences in different Asian societies. For example, daily life priorities in India are classified according to health, housing, food, work and family benefits; while this index (priorities of daily life) in China is prioritized in terms of health, housing, work, medical care and low crime rates. Therefore, communities should implement appropriate policies and sufficient investment in these sectors according to the time conditions and needs. In this way, many social, economic, environmental, and other disadvantages can be eliminated, and replaced by higher welfare and quality of life. It is also worth noting that many less developed countries in the Asian region need appropriate policies, development plans and prioritization in budgeting and investment.

Similarly, in Japan, daily life is prioritized in this way; That is, family health, work and employment, housing and the like. These issues have prevented many of the challenges and problems seen within other Asian societies from becoming an issue in Japanese society. This has led to the improvement of living standards, the improvement of generations, and the achievement of reformed characteristics in that society; That is, conditions that positively affect future generations. Priorities like this lead to different living conditions, different productivity rates, different loyalty rates, and ultimately different quality of life for citizens. Therefore, addressing the indicators related to health, hygiene, work, housing, etc., each in turn creates more opportunities. In other words, the promotion of public satisfaction depends on meeting the needs in the above and similar cases. Hence, Asian societies still have a long way to go to reach accepted and global standards. Demographic, economic, managerial and similar factors play an effective role in the realization of such plans and programs. Finally, achieving a higher quality of life has a series of feedback related to more production and loyalty to work and production, more work commitment and the like.

\section{Measuring normal life}

The bottom-up measurement method is of great importance in terms of measuring the quality of life of ordinary people. This index primarily and primarily measures how ordinary people pursue their lives according to their wants, needs, values and other desires. By measuring the quality of life between different strata, the different needs of these people can be assessed. Therefore, sociological studies and the application of sociodemographic indicators help to design and predict a more secure future by assessing the current situation. While Asian societies are constantly faced with new patterns due to the growth of their population as well as the expansion of urbanization in them, the adoption of appropriate social, economic and demographic policies is one of the top priorities of these societies. In this way, the quality of life between different strata can be improved, and accordingly, the level of commitment and interest of citizens can be increased compared to any time in the past. On the other hand, creating a kind of balance between urban and rural living increases self-commitment and increased productivity between citizens in urban and rural areas that complement each other, and thus the quality of life increases more rapidly.

This indicator depends on the relationship with family, neighbors, workplace, social institutions and the labor market. Creating connections between different institutions leads to a higher quality of life. This in itself means that by creating a connection between the mentioned sectors, the capacities and capabilities of individuals and citizens can be used in a desirable way. Today, many Asian countries, following the expansion of urbanization in them, as well as the adoption of new norms and urban and modern communication, in such a situation, many citizens with many cases of disorders caused by poor communication with social institutions, family, workplace and the like. They face it, which in itself negatively affects their quality of life.

The result of this relationship itself reflects the quality of life among citizens. Many Asian societies, which today face a steady stream of urban migration, find in China a situation for newcomers who cannot easily adapt to new norms and regulations, which in turn greatly affects their quality of life. Gives. Therefore, social health is also at great risk under such conditions. Many deviations, inappropriate relationships, and the like have emerged within this group of societies; That is, a phenomenon that itself requires more oversight, more investment, and more accurate foresight; In such a way that at least more immunity can be created for young people in the coming years. Otherwise, the next generation will also face challenges and irregularities in these societies.

Examining the Wave of Democratization in East and Southeast Asia (Huntington: 1991), Democracy in South Korea (Shin: 2003), and East Asian Democracy (Chu: 2003) generally measure the quality of life of its citizens. Over the last half century, such changes have taken place in many Asian societies that have greatly affected the quality of life itself. For example, following the expansion of population literacy; In particular, the spread of literacy among the female population has led to a significant share of the young population migrating to urban areas and manufacturing and industrial centers. This process has also affected many social indicators. Indicators such as more consumer items, utilization of various resources such as educational and cultural resources, resources related to leisure and the like, all of the above have been done following the democratization of these societies. The trend in general, while improving the quality of life among citizens, has also raised expectations. Hence, the current situation in the Asian region itself requires more demographic, social and economic forecasts for the coming years.

The study of European values by Halman et al. (Halman et al. 2007) and the Global Values Survey (Inglehart et al. 1998), which began in the 1960s and continues to this day, examine many It deals with life indicators and ultimately measuring quality of life. Therefore, non-European countries, including different parts of Asia, should always measure their quality of life indicators, and provide the basis for its improvement. Otherwise, many cases of crisis and socio-economic disorder will await such societies.

\section{Happiness and quality of life}

The quality of public life in Asian societies is also measured against happiness. Asian countries do not enjoy equal levels of happiness in terms of economic, social and cultural conditions. Therefore, different levels of quality of life can also be sought in these communities. In its Asian form, $65 \%$ of the people of Asian societies are known to be happy based on the indicators obtained. Cultural factors, how the economic situation, production and income each have their place in this index and how it plays a role. Among the 29 Asian communities studied, according to 
demographic, social, economic, etc., Brunei (in the Indian Ocean) is the happiest community, followed by the Maldives and Malaysia as other happy countries in the region. These countries also seem to show signs of happiness and joy within them. Calmness and characteristics of this kind have led to happiness within these countries. Therefore, the beds of happiness and joy in different forms and in different formats should be laid and designed. One of the tools that can be used to identify a happy society, or to expand and increase it, is topics such as sociology, family sociology, social studies, quality of life assessment, creating models for improving the quality of life and It is like that. Similarly, as far as demographics are concerned, by controlling the population and adopting new demographic patterns, the happiness index can be expanded as much as possible in a given society. In China, conditions can reduce poverty as much as possible, and thus replace a relatively affluent society.

In general, one of the needs of modern societies in which different age groups have a chance to live longer is to create and provide happiness in different dimensions and for different age groups. In other words, in this way, a satisfactory quality of life can be established for the young, middleaged and elderly age groups. A set of sciences such as demography, sociology, psychology and the like each play a role in creating happiness capital. On the other hand, according to many infrastructure indicators, the people of Tajikistan have the least happy life on the Asian continent, followed by Kazakhstan and Cambodia; That is, communities that express more happiness.

Similarly, while research on the quality of public life in Asia found that 15 countries in the region said they enjoyed their lives, 19 countries said they did not enjoy it as much. Many demographic, economic and other per capita factors play a role in the quality of life of citizens; That is, what makes them happy. Among this group of countries, Vietnam has declared the highest level of enjoyment of life, followed by Malaysia.

On the other hand, Taiwanese people are at a minimum in terms of having a pleasant life. Such fluctuations and changes in happiness bring with them different levels of quality of life. Therefore, in order to achieve the desired quality of life that leads to happiness, it is recommended to improve economic, social, public security and similar indicators. Providing each of the desired infrastructure requires sufficient investment, sufficient inputs, supervision, continuous management and the like.

\section{A variety of lifestyles}

Six types of lifestyle; that is, modern life, electronic (digital) life, religious life, world life, political life and family life have left different levels of life among different peoples of Asian societies; the people of these communities have different lifestyles under the influence of the above forms. As far as modern living and public facilities are concerned, Taiwanese people have the highest standard of living among the 29 selected Asian countries, while Burma has the lowest standard of living. Therefore, in order to achieve a higher quality of life, the way of life in proportion to time must always be modified and improved. On the other hand, the standard of living of digital and global life in the Asian region is not so high, except in special cases. As far as religious life is concerned, the ratio of religious affiliation is estimated to be very high in the 29 countries studied, with the exception of the Northeast Asian region.

In explaining political life, it should be added that more than $60 \%$ of respondents in 22 countries have declared from the statistical community, who participate in each round of general elections. Also, in explaining family life, it should be added that the family in most of the studied countries had an average of 4 or 5 members, $77 \%$ had private housing, and more than $90 \%$ in their housing, and from home food (Home-made). Such a sociological picture of the family and its related way of life reflects the different and improving quality of life in the study area. As Asia today pursues economic, social and industrial development projects in its various regions, this will pave the way for improving the quality of life for Asian countries in the coming years; Provided that the population and resources are in harmony with each other.

\section{Conclusion}

Asian countries are trying to access a satisfactory quality of life for the youth, the middle-aged, and the elderly people. Though the Asian countries are trying to establish quality of life for all, yet because of some infrastructures, some countries are observed to be in poverty. Some Asian countries are in minimum quality of life as far as their lifestyles are concerned. As new technologies are entering the Asian countries, they expect their quality of life to improve in the same way. As Asia today is pursuing economic, social and industrial development, it is optimistically projected to reach more improved quality of life in those countries. However, population and resources need to be harmonized in order to access desired quality of life.

\section{References:}

1. Barcaccia, Barbara.(2013) "Quality of Life: Everyone Wants It, But What Is It"? Forbes/ Education.

2. Chu, Y (2003) (May 6-7), The East Asian Democracy Barometers. Papers Presented at the Asia Barometer Symposium, Tokyo.

3. Commission of the European Communities, 2009, Communication from the Commission to the Council and the European Parliament, Brussels.

4. Costanza, R. et al (2009) Beyond GDP: The Need for New Measures of Progress. The Pardee Papers, January 4, Boston University.

5. Derek, G., 2009, "Quality of Life", Dictionary of Hunan Geography (5th ed.), Oxford: Black-well.

6. Halman et al(2007) Changing Values and Beliefs in 85 Countries: Trend from the Value Surveys from 1981 to 2004, Leiden: Brill.

7. Huntington, S. P (1991). The Third Wave: Democratization in the Late Twentieth Century, Norman University of Oklahoma Press.

8. Inglehart, R. et al., 1998, Human Values and Beliefs. A Crosscultural Sourcebook: Political, Religious, Sexual and Economic Norms in 43 Countries, Ann Arbor: University of Michigan Press.

9. Nussbaum, M., 1993, The Quality of Life, Oxford: Clarendon Press.

10. Sen, A., 1985, Commodities and Capablities, Amsterdam: North Holland.

11. Sen, A., 2000, Development as Freedom, Oxford: Oxford University Press.

12. Shin, D.C., 2003 (May 6-7), The Korea Democracy Barometer Surveys. Papers Presented at the Asia Barometer Symposium, Tokyo.

13. World Population Data Sheet 2012, PRB, Washington DC.

14. World Population Data Sheet, 2021, Population Reference Bureau, Washington DC. 